\title{
Study Outcome Measure Time Frame Text
}

National Cancer Institute

\section{Source}

National Cancer Institute. Study Outcome Measure Time Frame Text. NCI Thesaurus. Code C94094.

Time point(s) at which the study outcome measure is assessed. 